\title{
Proatherogenic immune responses are regulated by the PD-1/PD-L pathway in mice
}

\author{
Israel Gotsman, ${ }^{1}$ Nir Grabie,, ${ }^{1}$ Rosa Dacosta, ${ }^{1}$ Galina Sukhova, ${ }^{2}$ \\ Arlene Sharpe, ${ }^{3}$ and Andrew H. Lichtman ${ }^{1}$
}

\begin{abstract}
1Vascular Research Division, Department of Pathology, ${ }^{2}$ Donald W. Reynolds Cardiovascular Clinical Research Center, Department of Medicine, and ${ }^{3}$ Department of Pathology, Brigham and Women's Hospital and Harvard Medical School, Boston, Massachusetts, USA.
\end{abstract}

\begin{abstract}
T lymphocyte responses promote proatherogenic inflammatory events, which are influenced by costimulatory molecules of the $\mathrm{B} 7$ family. Effects of negative regulatory members of the $\mathrm{B} 7$ family on atherosclerosis have not been described. Programmed death-ligand 1 (PD-L1) and PD-L2 are B7 family members expressed on several cell types, which inhibit $T$ cell activation via binding to programmed death-1 (PD-1) on $T$ cells. In order to test whether the PD-1/PD-L pathway regulates proatherogenic $\mathrm{T}$ cell responses, we compared atherosclerotic lesion burden and phenotype in hypercholesterolemic $P D-L 1 / 2^{-/-} L D L R^{-/-}$mice and $L D L R^{-/-}$ controls. PD-L1/2 deficiency led to significantly increased atherosclerotic burden throughout the aorta and increased numbers of lesional $\mathrm{CD}^{+}$and $\mathrm{CD8}^{+} \mathrm{T}$ cells. Compared with controls, $P D-L 1 / 2^{-/-} L D L R^{-/-}$mice had iliac lymphadenopathy and increased numbers of activated $\mathrm{CD}^{+} \mathrm{T}$ cells. Serum levels of TNF- $\alpha$ were higher in $P D-L 1 / 2^{-/-} L D L R^{-/-}$mice than in controls. PD-L1/2-deficient APCs were more effective than control APCs in activating $\mathrm{CD}^{+} \mathrm{T}$ cells in vitro, with or without cholesterol loading. Freshly isolated APCs from hypercholesterolemic $P D-L 1 / 2^{-/-} L D L R^{-/-}$mice stimulated greater $\mathrm{T}$ cell responses than did APCs from hypercholesterolemic controls. Our findings indicate that the PD-1/PD-L pathway has an important role in downregulating proatherogenic $\mathrm{T}$ cell response and atherosclerosis by limiting APC-dependent $\mathrm{T}$ cell activation.
\end{abstract}

\section{Introduction}

Atherosclerosis is a chronic inflammatory disease in which T cellmediated immunity plays a significant component (1). Th cells are evident in the atherosclerotic plaque and have been shown to be important in the development of atherosclerosis $(2,3)$. T cellmediated immune responses toward specific plaque antigens such as oxidized LDL or HSP-60/65 may have an important role in the propagation of the inflammatory process $(4,5)$. The development of atherosclerosis in animal models is enhanced by proinflammatory Th1 cells, through the secretion of IFN- $\gamma(6,7)$.

$\mathrm{T}$ cell responses to antigen are modulated by members of the B7 family of molecules expressed on APCs, which bind to signaling receptors of the CD28 family expressed on the T cells. Some of these molecules provide positive costimulatory signals that promote $\mathrm{T}$ cell activation, and other members of these families transduce inhibitory signals that limit the $\mathrm{T}$ cell response. The major positive costimulatory pathway involves B7-1 and B7-2 (also known as CD80 and CD86, respectively), which bind to CD28 on T cells (8). ICOS is another CD28 family member, which binds ICOS ligand and transduces signals that promote $\mathrm{T}$ cell activation.

Other members of the B7 family and their corresponding receptors on $\mathrm{T}$ cells have an important role in modulating or downregulating $\mathrm{T}$ cell activation (9). CTLA-4, which is a CD28 family member expressed on $\mathrm{T}$ cells, binds B7-1 and B7-2 and induces negative signals that block T cell activation. Programmed death-1 (PD-1) is a CD28 family member on T cells that binds programmed death-ligand 1 (PD-L1) and PD-L2 (also known as B7-H1 and B7-DC, respectively) on APCs and transduces signals that

Nonstandard abbreviations used: acLDL, acetylated LDL; LDLR, LDL receptor; ORO, Oil red O; PD, programmed death; PD-L, programmed death-ligand.

Conflict of interest: The authors have declared that no conflict of interest exists. Citation for this article: J. Clin. Invest. 117:2974-2982 (2007). doi:10.1172/JCI31344. inhibit $\mathrm{T}$ cell immune-mediated responses $(10,11)$. PD-L1 and PD-L2 are highly expressed after antigen stimulation on APCs, specifically DCs, macrophages, and B cells (12). PD-1 on T cells is the only known receptor of these ligands $(12,13)$. Although there are reports suggesting that PD-L1 may have a stimulatory function (14), a receptor with such a function has yet to be found. Different B7/CD28 family members' costimulatory and regulatory pathways may have distinct effects on atherosclerosis, depending on the pattern of expression and the state of the immune system. We have previously shown that the costimulatory molecules B7-1 and B7-2 support proatherogenic $\mathrm{T}$ cell responses and the absence of B7-1 and B7-2 significantly reduce the lesion development in hematopoietically unmanipulated mice (15). Conversely, in the setting of radiated bone marrow chimeric $L D L R^{-/-}$mice, ablation of the B7-1/2-CD28 pathway impairs Treg development and enhances atherosclerosis (16). Similarly, we have found that deficiency of ICOS results in decreased Treg function, enhanced immune responsiveness, and more atherosclerosis in $L D L R^{-/-}$ bone marrow chimeric mice (17).

To our knowledge, the effects of negative regulatory pathways of the $\mathrm{B} 7 / \mathrm{CD} 28$ family on atherosclerosis have not previously been explored. We hypothesized that PD-L1 and PD-L2 function to downregulate $\mathrm{T}$ cell responses to plaque antigens and thereby limit atherosclerosis. To test this hypothesis, we generated PD-L1/ PD-L2/LDLR triple-knockout mice by cross-breeding PD-L1/PDL2 double-knockout mice with LDL receptor (LDLR) knockout mice, all on a C57BL/ 6 background. We then examined the influence of PD-L1/2 deficiency on the extent and phenotype of dietinduced atherosclerosis and plaque antigen-specific cell mediated responses in athero-prone LDLR-deficient mice. Our data demonstrate that the PD-1/PD-L pathway exerted a significant regulatory influence on the immune responses and atherosclerosis of hypercholesterolemic mice. 
Table 1

Mean weights and serum cholesterol

\begin{tabular}{|c|c|c|c|}
\hline & $\begin{array}{l}\text { Weight, } \\
6 \text { wk (g) }\end{array}$ & $\begin{array}{l}\text { Weight, } \\
16 \text { wk (g) }\end{array}$ & $\begin{array}{l}\text { Total serum } \\
\text { cholesterol, } \\
16 \text { wk (mg/d) }\end{array}$ \\
\hline $\begin{array}{l}P D-L 1 / 2^{-/-} L D L R^{-/-} \\
L D L R-/-\end{array}$ & $\begin{array}{l}20.4 \pm 0.6 \\
20.7 \pm 0.9\end{array}$ & $\begin{array}{l}29.8 \pm 1.4 \\
28.3 \pm 1.6\end{array}$ & $\begin{array}{l}1,362 \pm 78 \\
1,396 \pm 102\end{array}$ \\
\hline
\end{tabular}

There was no significant difference between the groups when comparing weight or serum cholesterol ( $n=14$ per group).

\section{Results}

Weights and serum cholesterol levels. There was no significant difference in mean weight between the control $L D L R^{-/-}$and $P D-L 1 / 2^{-/-}$ $L D L R^{-/-}$groups (Table 1). There were also no statistical differences in total serum cholesterol levels (Table 1) or cholesterol in specific lipoproteins (data not shown) between the 2 groups.

Quantitative analysis of atherosclerotic lesions. The absence of PD-L1 and PD-L2 led to markedly increased atherosclerotic burden in control $L D L R^{-/-}$mice on a high-cholesterol diet. This was evident at 5 and 10 weeks of high-cholesterol diet feeding (Figure 1). At 5 weeks of diet, the $P D-L 1 / 2^{-/-} L D L R^{-/-}$mice had a more than 2 -fold increase in aortic sinus atherosclerotic burden compared with control mice. Mean lesion areas were $96,080 \pm 22,320 \mu \mathrm{m}^{2}$ in control mice $(n=8)$ and $213,400 \pm 23,260 \mu \mathrm{m}^{2}$ in $P D-L 1 / 2^{-/-} L D L R^{-/-}$ mice $(n=7 ; P<0.01)$. Fractional lesion areas - the cross-sectional lesion area expressed as a fraction of the total aortic root sectional area - were $20.2 \% \pm 3.9 \%$ in control mice $(n=8)$ and $49.2 \% \pm 3.4 \%$ in $P D-L 1 / 2^{-/-} L D L R^{-/-}$mice $(n=7 ; P<0.001$; Figure $1 \mathrm{E})$. After 5 weeks of high-cholesterol diet, there were minimal atherosclerotic lesions in the aortic arch or descending aorta, and significant differences between the groups could not be ascertained at this age (data not shown). After 10 weeks of diet, there was a 2 -fold increase in aortic root disease and 3-fold increases in aortic arch and descending aorta disease (Figure 1, F-H). The mean lesion areas in the aortic sinus were $299,300 \pm 25,430 \mu \mathrm{m}^{2}$ in control mice $(n=13)$ and $569,300 \pm 35,410 \mu \mathrm{m}^{2}$ in $P D-L 1 / 2^{-/-} L D L R^{-/}$mice $(n=23 ; P<0.001)$. Fractional lesion areas were $47 \% \pm 2.5 \%$ in control mice $(n=13)$ and $73.2 \% \pm 2.3 \%$ in $P D-L 1 / 2^{-/-} L D L R^{-/-}$mice $(n=23 ; P<0.0001$; Figure $1 \mathrm{~F})$. The mean lesion sizes in the aortic arch were $40,710 \pm 9,115 \mu \mathrm{m}^{2}$ in control mice $(n=12)$ and 122,400 $\pm 16,820 \mu \mathrm{m}^{2}$ in $P D-L 1 / 2^{-1-} L D L R^{-/-}$mice $(n=23$; $P<0.01)$. Fractional lesion area increased from $20.7 \% \pm 2.8 \%$ in control mice $(n=12)$ to $50.3 \% \pm 3.4 \%$ in $P D-L 1 / 2^{-/-} L D L R^{-/-}$mice $(n=23$;

\section{Figure 1}

Effect of PD-L1/PD-L2 deficiency on atherosclerotic burden. (A and B) Representative cross sections of the ORO-stained aortic sinuses are shown for female $L D L R^{-1-}$ (Control) (A) and $P D-L 1 / 2^{-/-} L D L R^{-/-}$ $\left(P D-L 1 / 2^{--}\right)$mice $(B)$ after 10 weeks of high-cholesterol diet (original magnification, $\times 10)$. (C and D) Representative longitudinal sections of aortic arch are shown for female $L D L R^{-/-}(\mathbf{C})$ and $P D-L 1 / 2^{-/-}$mice (D) after 10 weeks of high-cholesterol diet (original magnification, $\times 100)$. (E-H) Quantitative analysis of lesions was performed on aortic roots taken after 5 weeks of high-cholesterol diet (E), and on aortic root $(\mathbf{F})$, aortic $\operatorname{arch}(\mathbf{G})$, and descending aorta fractional en face lesion area $(\mathbf{H})$, after 10 weeks of high-cholesterol diet. Each data point represents the mean value obtained for each mouse; horizontal bars represent the mean value for each group. ${ }^{\dagger} P<0.01,{ }^{\ddagger} P<0.001$, $\S P<0.0001$ versus control.
$P<0.001 ;$ Figure 1G). The en face lesional areas in the descending aorta were $1.7 \% \pm 0.2 \%$ in control mice $(n=6)$ and $5.5 \% \pm 0.8 \%$ in $P D-L 1 / 2^{-/-} L D L R^{-/-}$mice $(n=8 ; P<0.01$; Figure $1 \mathrm{H})$. Oil red $\mathrm{O}$ (ORO) staining revealed that $\mathrm{PD}-\mathrm{L} 1 / 2$ deficiency resulted in increased lipid content after 10 weeks of diet in the aortic sinus and arch. Aortic sinus lipid-positive areas were 25,080 $\pm 3,964$ $\mu \mathrm{m}^{2}$ in control mice $(n=13)$ and $56,610 \pm 5,598 \mu \mathrm{m}^{2}$ in $P D-L 1 / 2^{-/-}$ $L D L R^{-/-}$mice $(n=23 ; P<0.001)$. Aortic arch lipid-positive areas were 4,063 $\pm 1,057 \mu \mathrm{m}^{2}$ in control mice $(n=12)$ and 9,637 $\pm 1,605$ $\mu \mathrm{m}^{2}$ in $P D-L 1 / 2^{-/-} L D L R^{-/-}$mice $(n=23 ; P<0.05)$.

Phenotypic analysis of atherosclerotic lesions. Analysis of the cellular content in atherosclerotic lesions in both groups of mice was determined by specific immunostaining in aortic sinus sections. The results of quantification of the positively stained areas are shown in Figure 2.

After 10 weeks of high-cholesterol diet feeding, there was a 3 -fold increase in $\mathrm{CD}^{+} \mathrm{T}$ cells as well as a marked increase in $\mathrm{CD}^{+}$ $\mathrm{T}$ cell infiltration in the intima of $P D-L 1 / 2^{-/-} L D L R^{-/}$mice compared with control mice (Figure 2). In addition, there was a 2-fold
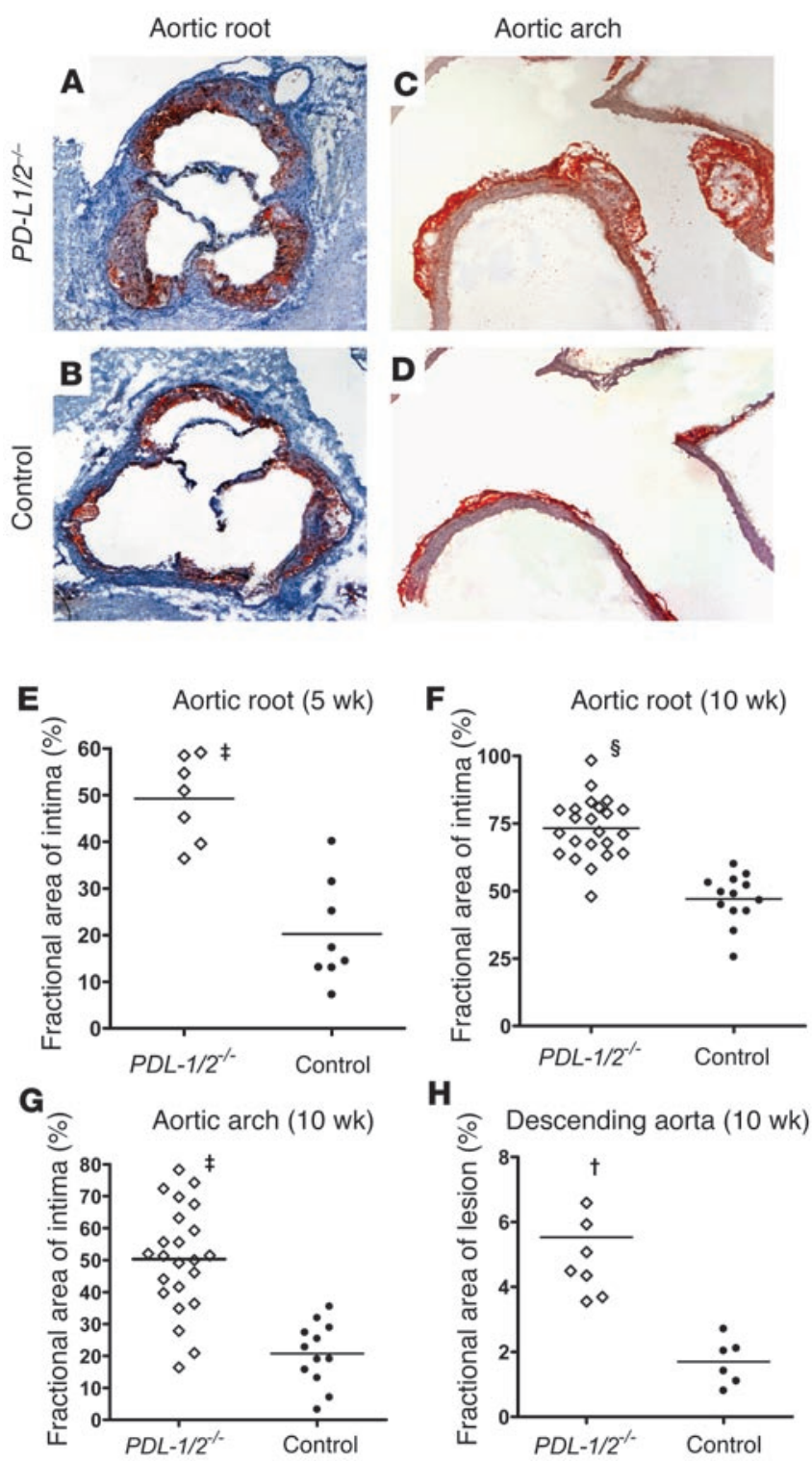
A

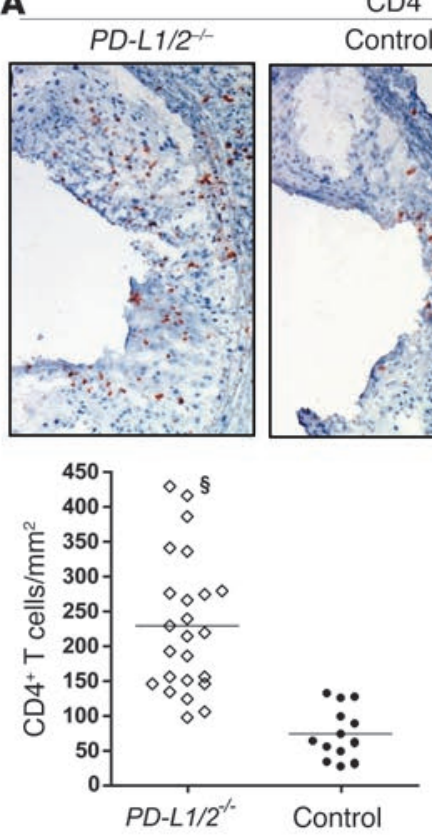

CD4
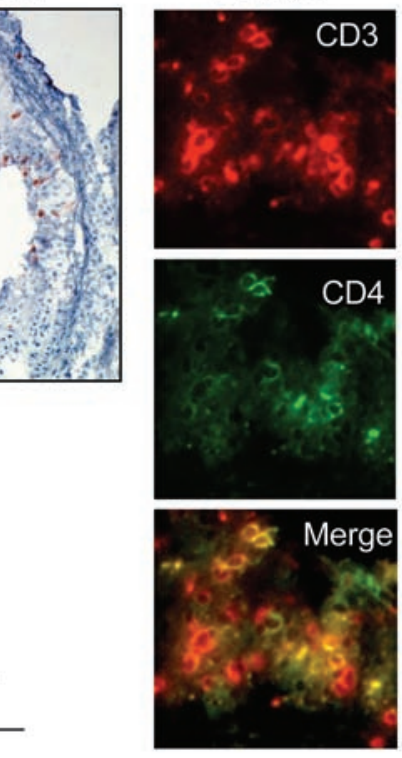

B

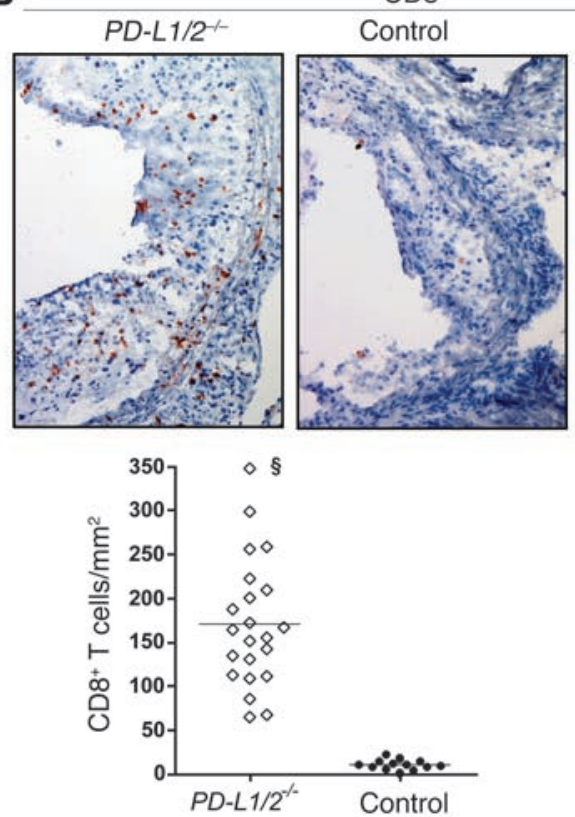

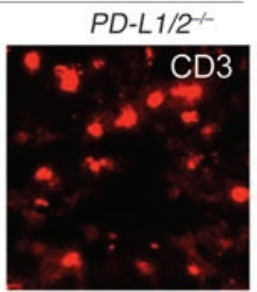
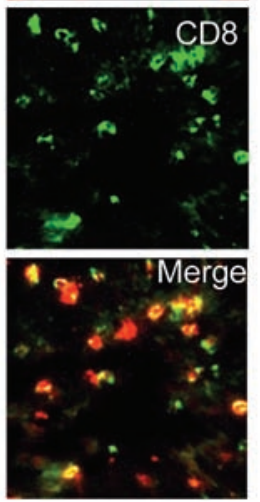

C
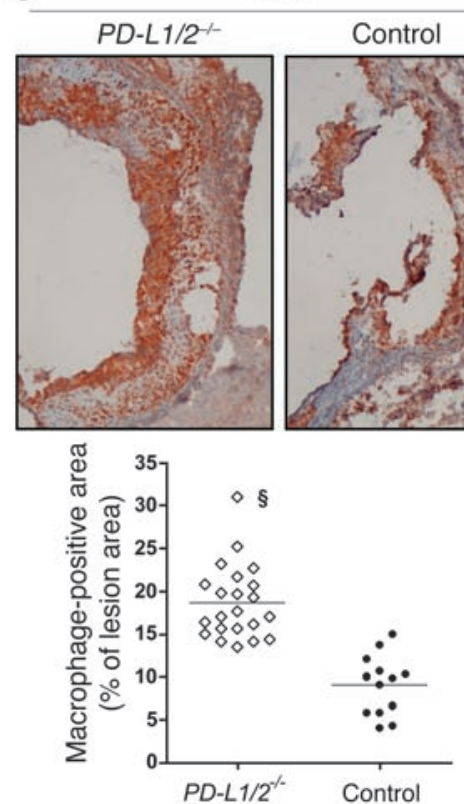

D
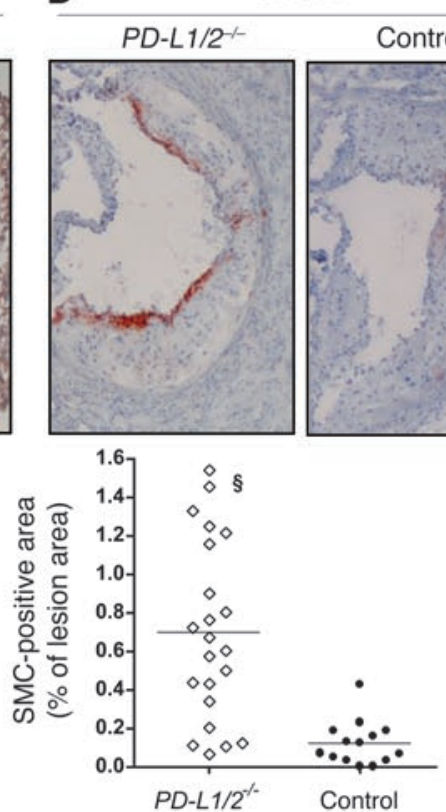

E

$P D-L 1 / 2^{-1}$

Collagen
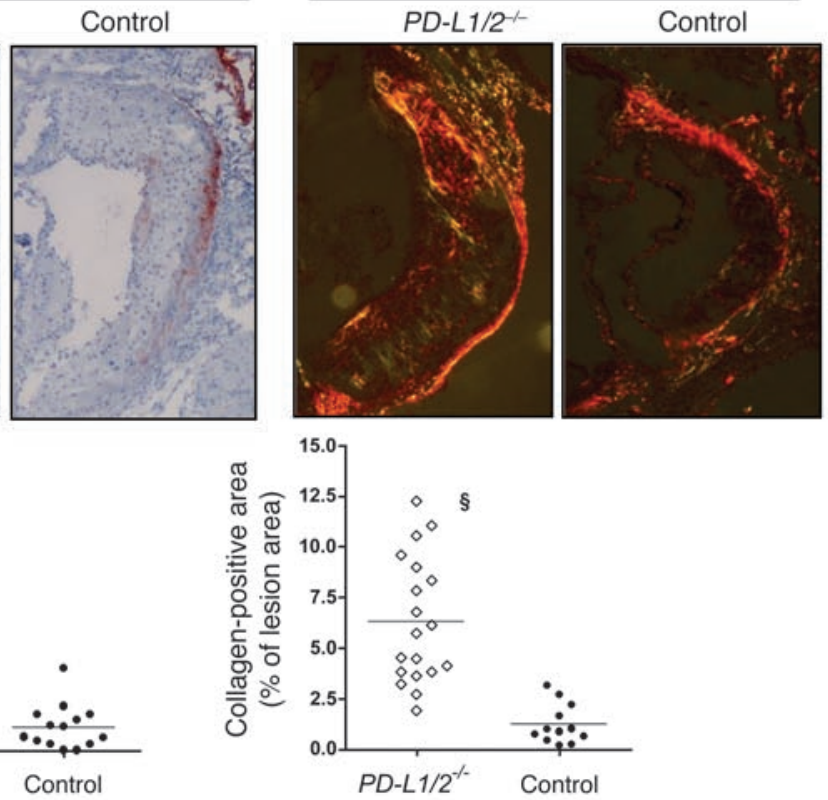

Figure 2

Effect of PD-L1/2 deficiency on atherosclerotic phenotype. Representative sections of aortic sinus (adjacent to the ORO-stained sections in Figure 1) were immunohistochemically stained with antibodies specific for CD4 (A), CD8 (B), Mac3 for macrophages (C), and smooth muscle actin for smooth muscle cells (D). Collagen types I and III were stained by Picrosirius red, and the sections were analyzed by polarization microscopy (E). For each molecule, representative immunohistochemically stained sections (original magnification, $\times 200$ ) and quantitative analysis of the staining for each experimental group are shown. Each data point represents the mean value determined for each mouse; horizontal bars represent the mean value for each group. Two-color immunofluorescence-stained sections from $P D-L 1 / 2^{-/-} L D L R^{-/-}$mice are also shown using antibodies specific for CD3 (red) plus CD4 or CD8 (green). Double-stained cells appear yellow in the merged image. Sections are shown for each type of stain. $\$ P<0.0001$ versus control.

increase in macrophage content as well as a significant increase in smooth muscle cell content and collagen deposition in the lesions of the $P D-L 1 / 2^{-/-} L D L R^{-/-}$mice (Figure 2 ). These differences were also significant when atherosclerosis was evaluated according to gender. These data clearly demonstrate that the absence of PD-L1/2 increases inflammatory cell infiltration in atherosclerotic lesions, and this is associated with more smooth muscle cell infiltration or proliferation and more collagen deposition. 
A

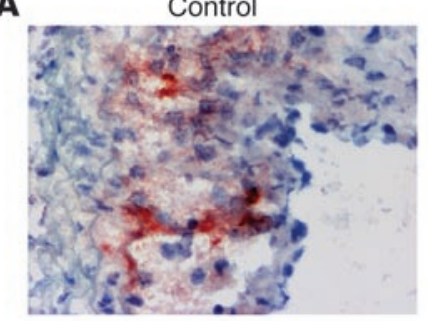

B
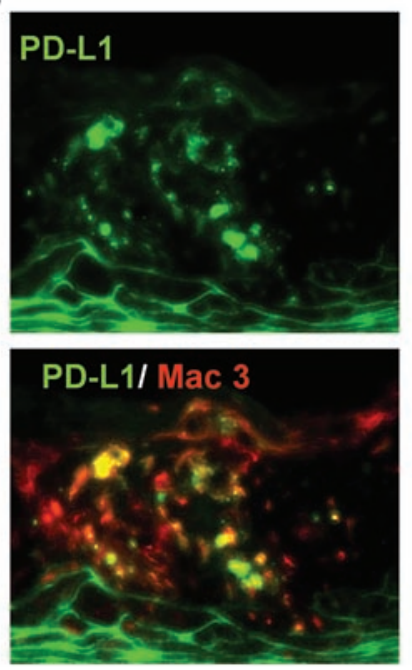

$P D-L 1 / 2^{--}$
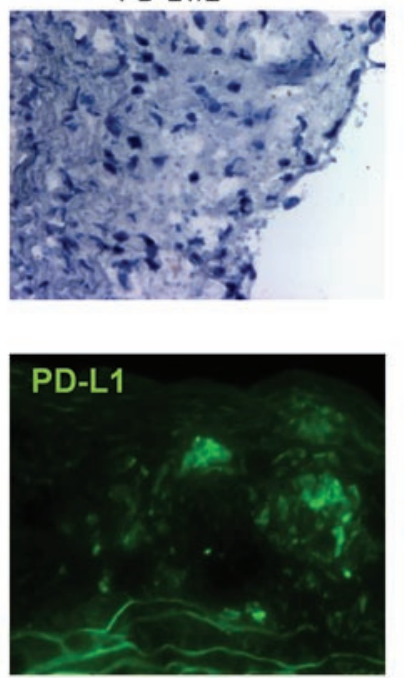

PD-L1/ CD11C

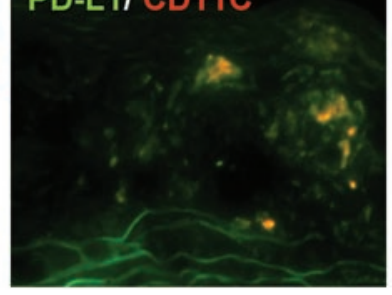

Expression of PD-L1 in bypercholesterolemic mice. PD-L1 is expressed on hematopoietic APCs $(12,18)$ and endothelium in inflammatory tissues, and this local expression may be important in the inhibitory function of this molecule $(19,20)$. Furthermore, PD-L1 is constitutively expressed on APCs, but is upregulated in states of immune activation (12), including during immune-mediated diseases (21). Because PD-L1/2 deficiency clearly increased atherosclerosis in

\section{Figure 3}

Expression of PD-L1 in atherosclerotic lesions. (A) PD-L1 was detected by immunohistochemistry in aortic sinus lesions of control $L D L R^{-1-}$ mice after 10 weeks of high-cholesterol diet. The same tissues from $P D-L 1 / 2^{-1-} L D L R^{-/}$mice did not stain, and served as negative controls. Original magnification, $\times 400$. (B) Two-color immunofluorescence stains for PD-L1 (green) and either CD11c or Mac3 (red) were performed on cholesterol aortic sinus lesions of $L D L R^{-/-}$mice fed cholesterol-containing diet for 10 weeks. Top: PD-L1 staining alone. Bottom: Combined PD-L1 and MAC3 or PD-L1 and CD11c stains, in which superimposed stains appear yellow.

LDLR-null mice, we asked whether PD-L1 expression is influenced by the hypercholesterolemic environment and whether it is expressed at the local level of the atherosclerotic lesion. We found PD-L1 expression by immunohistochemistry in aortic lesions (Figure 3A). Using 2-color immunofluorescence microscopy, we found PD-L1 on both DCs and macrophages (Figure 3B). Although PD-L1 is not abundantly expressed, and only some lesional macrophages are stained, PD-L1 was consistently found in most lesions, including those in the aortic sinuses and aortic arches.

We also examined the expression of PD-L1 and PD-L2 on DCs from the iliac lymph nodes, which may drain the descending aorta. Other lymph nodes were not examined. The fraction of PD-L1-expressing DCs in these nodes was increased in mice fed a high-cholesterol diet for 10 weeks compared with control diet-fed mice (Figure 4A). The expression of PD-L2 was not significantly different between the 2 groups. High-cholesterol diet feeding also led to a significant increase in the percentage of iliac lymph node DCs expressing the costimulatory molecule B7-1, and this increase was seen after 3 and 10 weeks of high-cholesterol diet. These data would suggest that these molecules are upregulated as the inflammatory events associated with atherosclerosis develop. We also examined the effect of high-cholesterol diet on the expression of PD-L1, PD-L2, and B7-1 in peritoneal macrophages. An increase in the number of PD-L1-expressing peritoneal macrophages was seen in $L D L R^{-/-}$mice fed high-cholesterol diet for 10 weeks compared

\section{Figure 4}

Hypercholesterolemia results in increased PD-L1, PD-L2, and B7-1 expression by APCs. $L D L R^{-/-}$mice were fed control diet (con) or cholesterol-containing diet for 3 or 10 weeks before sacrifice and tissue harvesting. lliac lymph node cell suspensions (A) and peritoneal macrophages (B) were stained with fluorescent antibodies specific for CD11C and F4/80, respectively, and both populations were also stained with fluorescent antibodies specific for PD-L1, PD-L2, and B7-1. Values represent the percentage of the $\mathrm{CD} 11 \mathrm{c}^{+}$or $\mathrm{F} 4 / 80^{+}$cells that stained positive for the indicated antibodies. ${ }^{*} P<0.05,+P<0.01$ versus control diet. $n=4$ per group. Data are from 1 of 2 experiments with similar results. (C) ORO staining for lipid in peritoneal macrophages isolated from mice on cholesterol or control diets. Original magnification, $\times 100$.
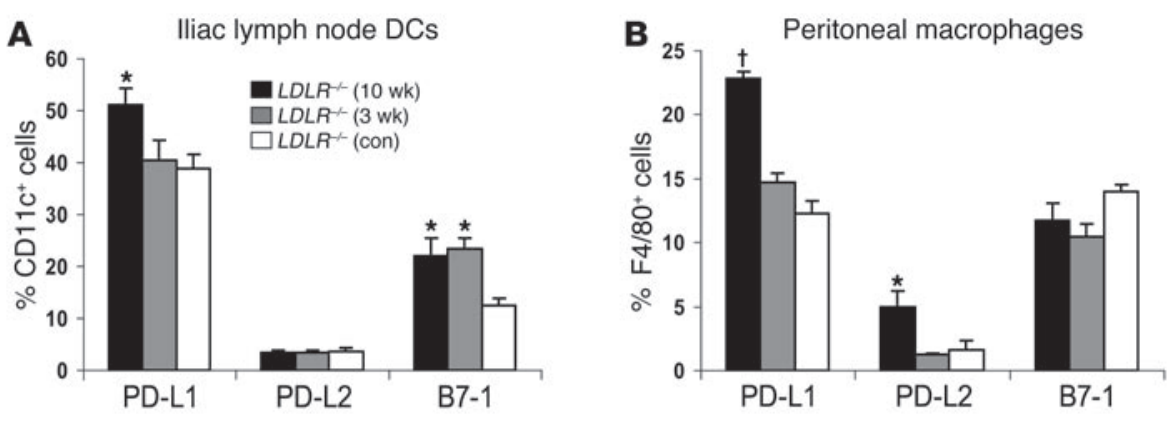

C

Peritoneal macrophages

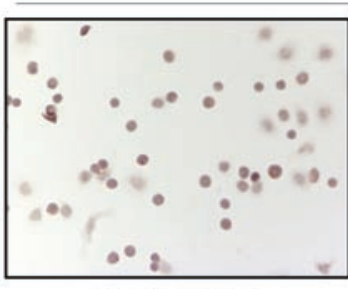

$L D L R^{-/}$(con)

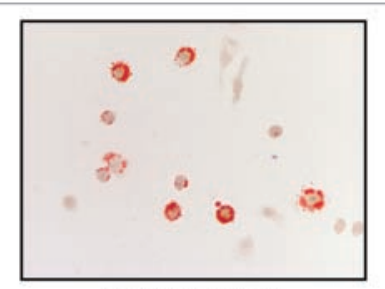

$L D L R^{-/}(3 \mathrm{wk})$

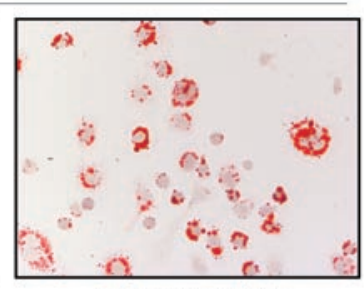

$L D L R^{--}(10 \mathrm{wk})$ 

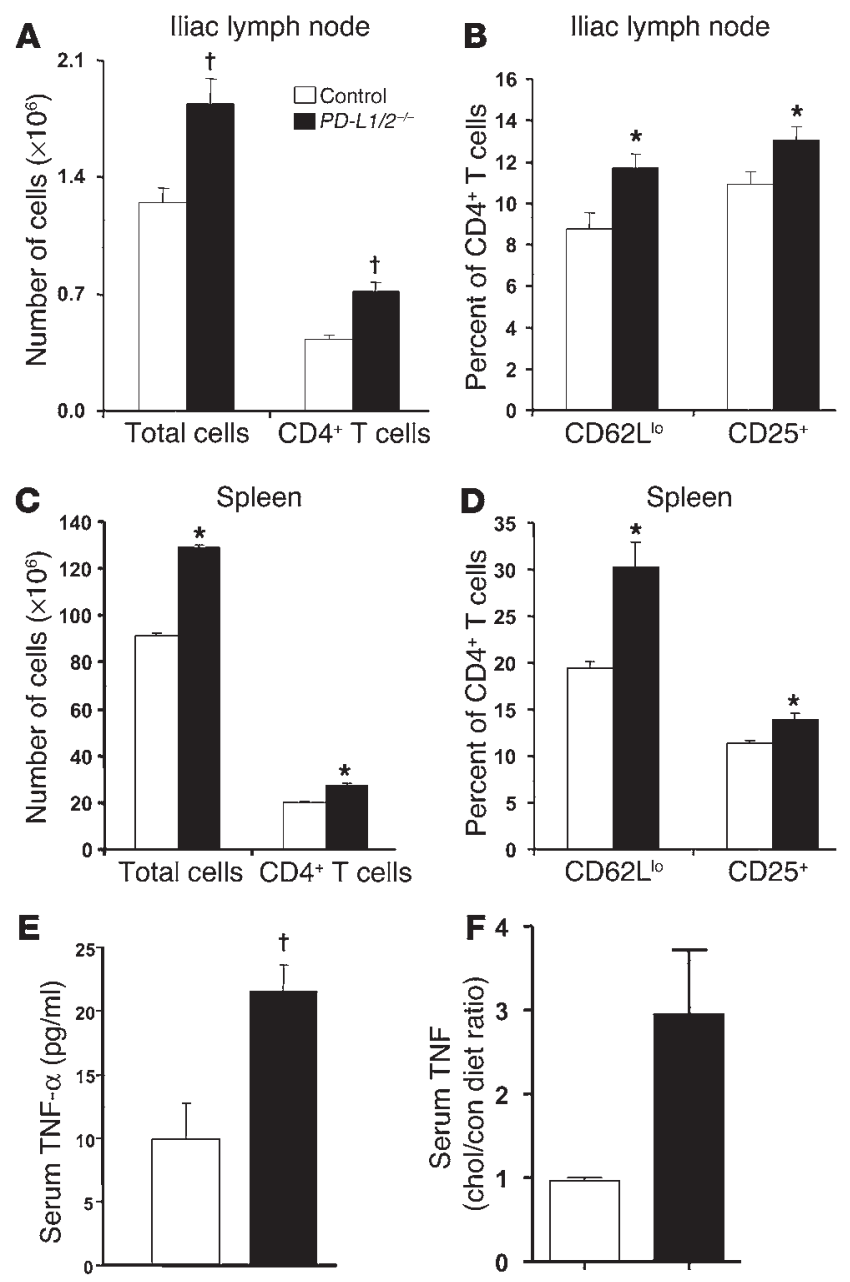

with control diet-fed mice (Figure 4B). An increase was also noted in PD-L2 expression after high-cholesterol diet feeding. There was no significant difference in macrophage B7-1 expression. The macrophages isolated from mice fed high-cholesterol diet were lipid-loaded foam cells, as confirmed by lipid staining (Figure 4C). These cells have been studied as accessible surrogates for the lipidladen macrophages present in atherosclerotic lesions (22). We did not find any significant high-cholesterol diet-induced changes in the expression of PD-L1, PD-L2, or B7-1 on DCs or macrophages isolated from spleen (data not shown).

Effect of PD-L1/2 deficiency on T cell activation in vivo. In order to evaluate the changes in T cell activation in the absence of PD-L1/2 in the context of atherosclerosis, we examined iliac lymph nodes and spleens from $P D-L 1 / 2^{-/-} L D L R^{-/-}$mice fed a high-cholesterol diet compared with $L D L R^{-/-}$control mice fed the same diet. After 5 weeks of high-cholesterol diet, the iliac lymph nodes appeared larger in $P D-L 1 / 2^{-/-} L D L R^{-/-}$mice than in control $L D L R^{-/-}$mice. This was confirmed by increased average cell content in these lymph nodes (Figure $5 \mathrm{~A}$ ). The total number of CD4 ${ }^{+} \mathrm{T}$ cells in the lymph nodes increased in hypercholesterolemic $P D-L 1 / 2^{-/-} L D L R^{-/-}$ mice compared with controls. A higher fraction of the $\mathrm{CD} 4^{+} \mathrm{T}$ cells from $P D-L 1 / 2^{-/-} L D L R^{-/-}$mice had an activation phenotype $\left(\mathrm{CD} 25^{+} \mathrm{CD} 62 \mathrm{~L}^{\mathrm{lo}}\right)$ compared with $\mathrm{CD}^{+} \mathrm{T}$ cells from control mice (Figure 5B). Other lymph nodes were not examined. The $P D-L 1 / 2^{-/-}$ $L D L R^{-/-}$mice also had enlarged spleens with increased total cell

\section{Figure 5}

PD-L1/2 deficiency results in enhanced immune responses in hypercholesterolemic mice. (A and $\mathbf{C}$ ) The number of total cells and cells in the CD4+ $\mathrm{T}$ subset was evaluated by FACS staining of cell suspensions prepared from the iliac lymph nodes $(\mathbf{A})$ and spleens $(\mathbf{C})$ of $P D-L 1 / 2^{-/-} L D L R^{-/-}$and $L D L R^{-/-}$mice after 5 weeks of high-cholesterol diet. (B and $\mathbf{D})$ The expression of T cell activation markers CD25 and CD62L in cells from the iliac lymph nodes (B) and spleens (D) from mice of each experimental group were determined by FACS analysis. Percentages were evaluated on gated $\mathrm{CD} 4+\mathrm{T}$ cells. $n=6$ per group. (E) Serum levels of the proinflammatory cytokine TNF- $\alpha$ at time of sacrifice were determined. $n=10-14$ per group. (F) Ratio of the serum TNF- $\alpha$ level in mice fed high-cholesterol diet to that of mice fed control diet in both $P D-L 1 / 2^{-1-} L D L R^{-/-}$and $L D L R^{-1-}$ mice. $n=3$ per genotype and diet group. Data are mean \pm SEM. ${ }^{*} P<0.05,{ }^{\dagger} P<0.01$ versus control.

numbers (Figure 5C), as well as a higher fraction of $\mathrm{CD} 4^{+} \mathrm{T}$ cells with an activated cell-surface phenotype (Figure 5D), similar to what was seen in the iliac lymph nodes. Differences in the number and activation phenotypes of $\mathrm{CD}^{+} \mathrm{T}$ cells were also observed after 10 weeks of high-cholesterol diet (data not shown).

Serum levels of cytokines. We looked for evidence of systemic immune activation in $P D-L 1 / 2^{-/-} L D L R^{-/-}$mice by examining serum levels of pro- and antiinflammatory cytokines after 10 weeks of high-cholesterol diet. We found a significant increase in TNF- $\alpha$ in the serum of $P D-L 1 / 2^{-/-} L D L R^{-/}$mice compared with the control mice (Figure $5 \mathrm{E})$, but no significant differences in the serum levels of IFN- $\gamma$, IL-10, IL-12, IL-6, or MCP-1. When we examined the ratio of serum TNF- $\alpha$ in high-cholesterol diet- versus control diet-fed mice, we found that high-cholesterol diet-induced elevation of serum TNF- $\alpha$ was seen only in the setting of PD-L1/2 deficiency (Figure 5F).

Effect of PD-L1/2 deficiency on APC activation of T cells. We examined the effects of PD-1 ligand deficiency on antigen-specific activation of T cells, using a well-characterized TCR transgenic $\mathrm{T}$ cell model system. Naive CD4 ${ }^{+}$OVA-specific TCR transgenic T cells were isolated from OT-II mice (23) and were stimulated in vitro with peritoneal macrophages from mice lacking PD-L1/2. We first evaluated differences without lipid loading, and then further evaluated whether differences were evident after loading the macrophages for 5 hours with acetylated LDL (acLDL) prior to stimulating $\mathrm{T}$ cells as previously described (24). As expected, peritoneal macrophages isolated from $P D-L 1 / 2^{-/-}$mice caused increased $\mathrm{CD}^{+} \mathrm{T}$ cell proliferation compared with control mice (Figure 6A). Importantly, this was also evident after lipid loading. This increase occurred when $\mathrm{T}$ cells were stimulated with the polyclonal stimulus anti-CD3 as well as with $5 \mu \mathrm{g} / \mathrm{ml}$ of cognate OVA peptide antigen. However, at a higher antigen concentration $(10 \mu \mathrm{g} / \mathrm{ml})$ plus lipid loading, there was no significant influence of PD-L1/2 deficiency. This is consistent with previous data showing that the downregulating effect of PD-L1/2 on CD4 ${ }^{+} \mathrm{T}$ cells is greatest at lower antigen concentrations (11). Because DCs have been implicated in $\mathrm{T}$ cell responses in atherosclerosis $(25,26)$, we also performed studies with PD-L1/2-deficient DCs. As seen with the macrophages, there was an increased $\mathrm{T}$ cell proliferative response using DCs isolated from PD-L1/2-deficient mice compared with control mice, with or without lipid loading. This was evident at a minimal DC/T cell ratio of 1:10 (Figure 6B). However, at a DC/T cell ratio of $1: 1$, this effect of PD-L1/2 deficiency was not apparent (data not shown), again suggesting that the inhibitory effect of PD-L1/2 on T cell activation can be overridden by 


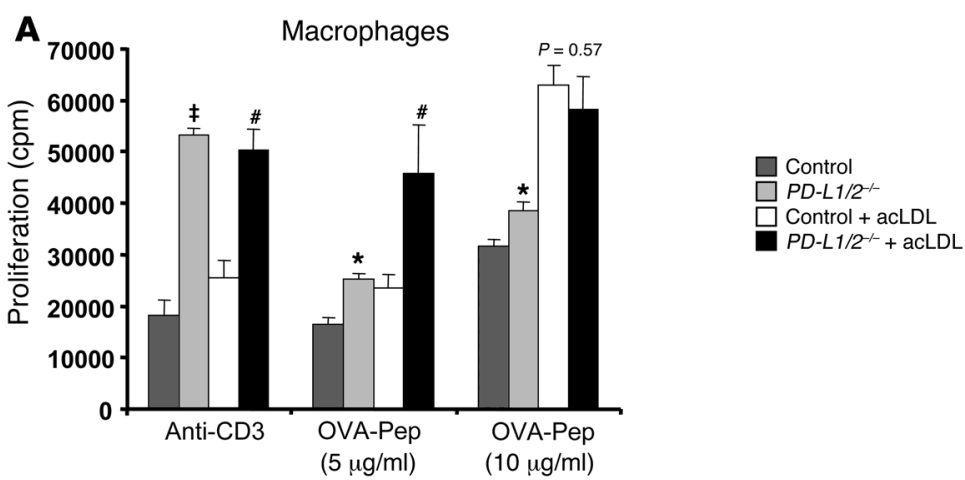

\section{Figure 6}

PD-L1/2 deficiency results in enhanced CD4+ $T$ cell responses to APCs in vitro. Proliferative response of OVA peptide-specific CD4+ cells were measured when cultured with wildtype C57BL/6 (Control) or PD-L1/2-/- APCs with or without lipid loading with acLDL in the presence of anti-CD3 or antigen stimuli. OVA pep, OVA peptide. (A) APCs were peritoneal macrophages (macrophage/T cell ratio, 2:1). (B) APCs were splenic DCs (DC/T cell ratio, $1: 10)$. Incorporation of $[3 \mathrm{H}]$-thymidine was determined at 64 hours. (C and D) Cytokine secretion by the CD4+ cells cultured with DCs was measured in 48-hour supernatants. $n=3$ per group. Data are mean \pm SEM. ${ }^{\star} P<0.05$, $\dagger P<0.01, \ddagger P<0.001$ versus control; $\uparrow P<0.05$, $\# P<0.01$ versus control plus acLDL.
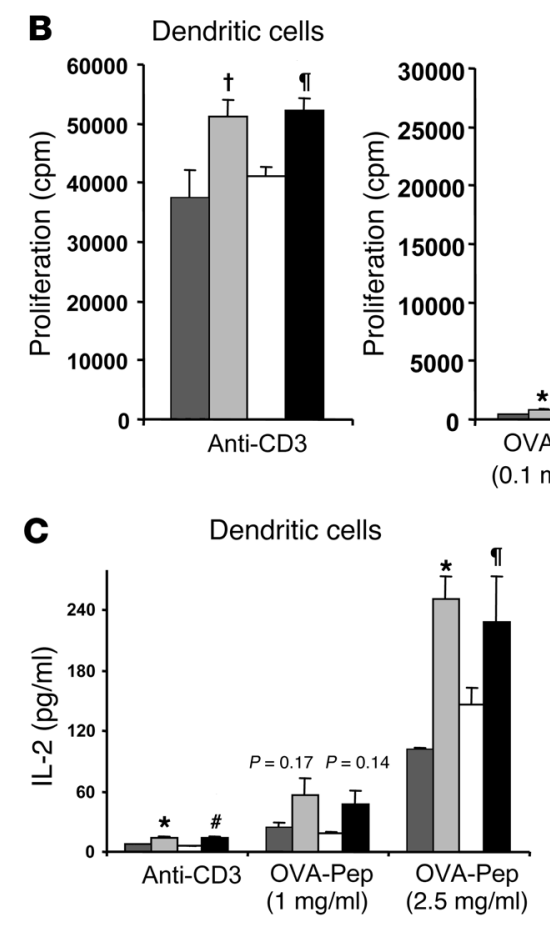

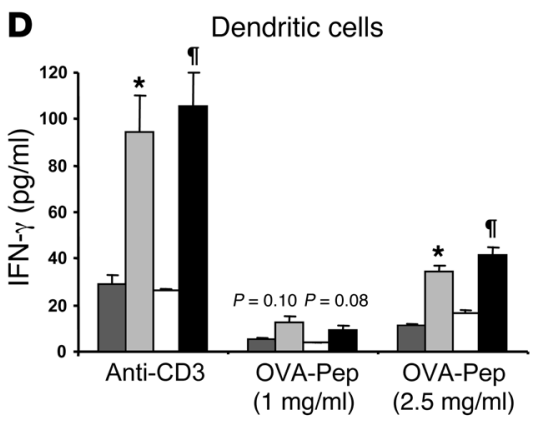

stronger antigenic stimuli. IFN- $\gamma$ secretion in these T cells was also increased in response to activation by DCs from $P D-L 1 / 2^{-/-}$ mice (Figure 6D). This was evident even at high stimuli that did not show difference in proliferative response (DC/T cell ratio of $1: 1$; data not shown), suggesting that the effector function of the $\mathrm{T}$ cells is tightly regulated by $\mathrm{PD}-\mathrm{L} 1 / 2$ even when proliferation is overridden by strong activation stimuli.

We also analyzed the influence of PD-L1/2 on T cell activation when mixed splenic APCs were freshly isolated from hypercholesterolemic mice. In these experiments, the T cell-depleted spleen cells were isolated from $P D-L 1 / 2^{-/-} L D L R^{-/-}$or $L D L R^{-/-}$control mice after 10 weeks of high-cholesterol diet. These APCs were cultured with $\mathrm{CD}^{+} \mathrm{T}$ cells isolated from hypercholesterolemic $L D L R^{-/-}$mice in order to ensure the presence of oxidized LDL-specific T cells. We found these $\mathrm{CD}^{+} \mathrm{T}$ cells had a significantly greater proliferative response to anti-CD3 in the presence of APCs from $P D-L 1 / 2^{-/-}$ $L D L R^{-/-}$mice compared with those from $L D L R^{-/-}$mice (Figure 7A). The increase in the proliferation response was also seen in response to oxidized LDL (Figure 7B), although the proliferative response was relatively weak. The increased response was also seen with specific antigenic stimuli using OVA-specific OT-II T cells (Figure 7C).
The increased response was also evident when analyzing IL-2 and IFN- $\gamma$ secretion by $T$ cells stimulated with PD-L1/2-deficient APCs plus anti-CD3 or OVA peptide (Figure 7, D and E).

\section{Discussion}

This study demonstrates a profound influence of the PD-L1/2 molecules on $\mathrm{T}$ cell responses and atherosclerosis in hypercholesterolemic mice. Without inflammatory challenges, $P D-L 1 / 2^{-/-}$mice do not show overt manifestations of dysregulated immunity for many months. However, in the setting of infections, allografts, or preexisting susceptibility to autoimmunity, the absence or blockade of PD-L1, PD-L2, or PD-1 result in enhanced T cell responses and disease (18, 27-30). Our results indicate that hypercholesterolemia and the resulting arterial pathology represent another systemic immune challenge that is regulated by the $\mathrm{PD}-\mathrm{L} 1 / 2$ pathway.

We chose to study the effects of combined deficiency of PD-L1 and PD-L2 because the differential roles of these molecules remain unclear, and redundant functions might minimize the net effect of a single gene deficiency. Furthermore, our previous work with cultured mouse endothelial cells and mouse hearts indicates that PD-L1 plays a dominant role in regulating $\mathrm{T}$ cell responses to 

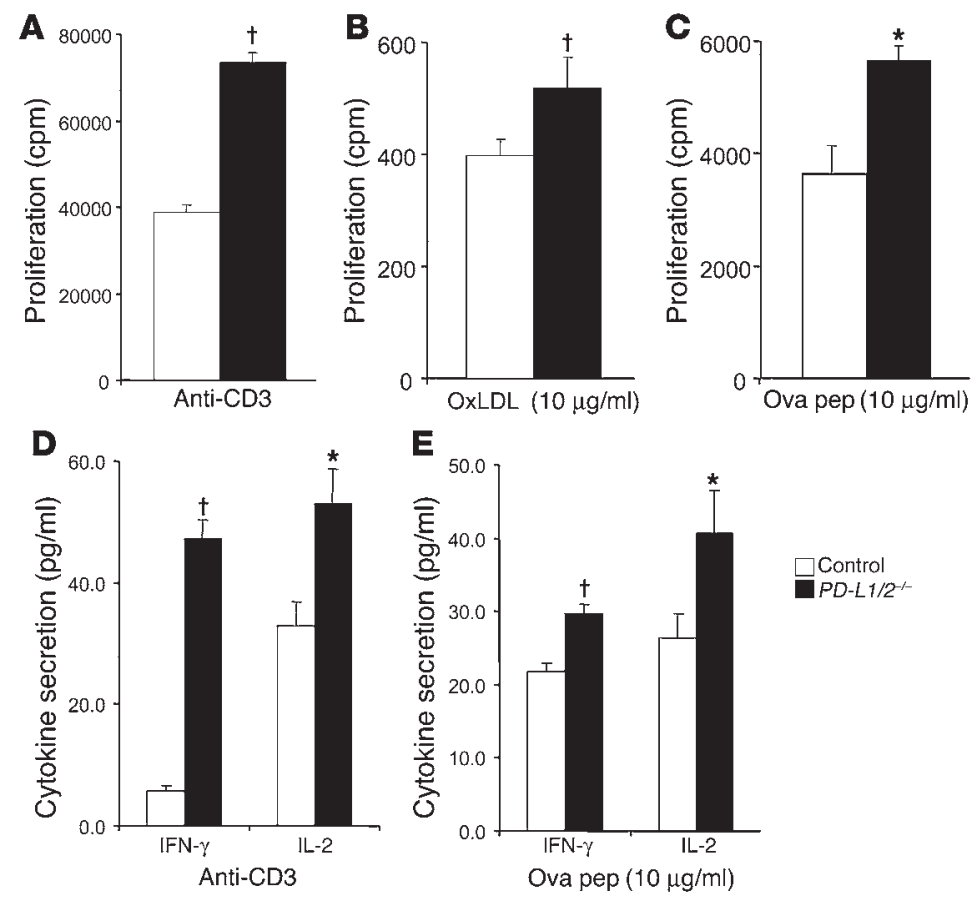

E

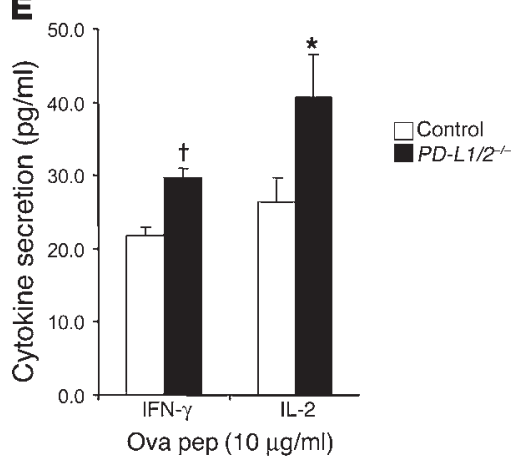

\section{Figure 7}

APCs isolated from hypercholesterolemic $P D-L 1 / 2^{-1-} L D L R$ mice are more potent T cell stimulators than are APCs isolated from hypercholesterolemic $L D L R^{-/-}$mice. (A-C) T cells were isolated from spleens of $L D L R^{-/-}$mice after 10 weeks of high-cholesterol diet and were cultured with $T$ cell-depleted APCs isolated from spleens of $P D-L 1 / 2^{--} L D L R^{-/-}$and $L D L R^{-/-}$ mice, plus $1 \mu \mathrm{g} / \mathrm{ml}$ anti-CD3 (A) or $10 \mu \mathrm{g} / \mathrm{ml}$ oxidized LDL (OxLDL; B). Proliferative responses of the $\mathrm{CD}^{+}{ }^{+}$were determined by [3H]-thymidine incorporation at 72 hours $(n=6$ per group). (C) The same APCs were also cultured with OVA peptide-specific CD4+ $\mathrm{T}$ cells (OT-II) plus antigen, and proliferative responses were measured in the same way. (D and E) Cytokine levels were measured in 48-hour supernatants of the CD4 ${ }^{+} T$ cells cultures stimulated with anti-CD3 (D) or OVA peptide $(E)$ as described above. Data are mean \pm SEM. $n=6$ per group. ${ }^{\star} P<0.05,{ }^{\dagger} P<0.01$ versus control. cardiovascular antigens (20). Nonetheless, differential effects of PD-L1 and PD-L2 have been demonstrated in some mouse disease models, albeit in strain-specific manners. These diseases include cutaneous Leishmaniasis (28), EAE, and diabetes (29). This raises the possibility that combined deficiency of PD-L1 and PD-L2 may obscure opposing effects of each molecule. The marked effects of combined PD-L1 and PD-L2 deficiency on APC function and on atherosclerosis we observed in this study support the conclusion that there are not opposing influences of these 2 molecules of comparable magnitude on the immune responses that affect atherosclerosis, at least in the C57BL/6 strain.

Our finding that deficiency of PD-L1/2 increased atherosclerosis is comparable to the exacerbating effects of deficiency of this pathway in other immune-mediated diseases such as EAE and insulitis $(18,19,31)$. Specifically, the data from this study would suggest that the effect of PD-L1/2 deficiency is mediated largely through dysregulated T cell activation by APCs. We demonstrated this in vitro with normal and lipid-loaded DCs and macrophages as well as with APCs freshly isolated from atherosclerotic mice. In all cases, there was more proliferation in the absence of PD-L1/2; more importantly, there was increased secretion of IFN- $\gamma$, a cytokine that has previously been shown to have a crucial role in the propagation of atherosclerosis (7). An alternative way in which PD-L1/2 deficiency might lead to enhanced proatherogenic T cell responses is by impairment of Treg development or function. B7 family molecules have been shown to support natural Treg-mediated suppression of proatherogenic immune responses $(16,17)$. Although PD-L1 has been implicated in the development of type 1 Tregs (32), there are no data clearly indicating a role for PD-L1 or PD-L2 in natural Treg suppression. Furthermore, using an in vitro assay, we did not observe an impairment in the suppressive function of natural Tregs isolated from PD-L1/2-deficient mice (data not shown).

The site where PD-L1/2 may be inhibiting proatherogenic T cell responses remains unclear. We show here that hematopoietically derived APCs from spleen and paraaortic lymph nodes relied on $\mathrm{PD}-\mathrm{L} 1 / 2$ to limit $\mathrm{T}$ cell activation. This has also been shown in other models of immune-mediated diseases (18). However, there are data to suggest that PD-L1 may have an inhibitory function within tissue inflammatory sites (19). We have previously shown that PD-L1 is expressed on endothelial cells and inhibits T cell activation (20). In addition, PD-L1 is expressed on microvascular endothelial cells (21, 33) as well as on pancreatic islet cells (31) and tubular epithelium (34). Although we found PD-L1 in the neointima of atherosclerotic lesions, this likely reflects expression on lesional DCs or macrophages. It is possible that the increased number of T cells we observed in the lesions of PD-L1/2-deficient mice is a result of increased recruitment, increased local proliferation, or both. The possibility that PD-L1/2 on APCs within the plaque may regulate local effector $T$ cell proliferation or effector responses requires further study.

Although a significant body of literature supports the hypothesis that $\mathrm{CD}^{+} \mathrm{T}$ cell responses promote atherogenesis (5), the effects of hypercholesterolemia are not uniformly conducive to enhanced T cell-mediated immunity $(35,36)$. Furthermore, the role of different $\mathrm{T}$ cell subsets in atherogenesis is complex (37), with many questions unresolved. Our finding that $\mathrm{CD}^{+} \mathrm{T}$ cell infiltration in atherosclerotic lesions was markedly enhanced in PD-L1/2-deficient mice is of interest, because $C D 8^{+} \mathrm{T}$ cells are usually scarce in lesions compared with $\mathrm{CD}^{+} \mathrm{T}$ cells (1). Recent studies have shown that PD- 1 is upregulated on $\mathrm{CD}^{+} \mathrm{T}$ cells in the setting of chronic viral infections, leading to an "exhausted" phenotype characterized by functional impairment of the T cells $(28,38-40)$. Blockade of PD-1 can reverse this exhausted phenotype $(38,39)$. The $\mathrm{CD}^{+} \mathrm{T}$ cell infiltration in atherosclerotic lesions of PD-L1/2-deficient mice suggests that a similar mechanism of reversible inhibition of $\mathrm{CD}^{+} \mathrm{T}$ cells responses exists in the chronic inflammatory milieu of atherosclerosis.

The PD-1/PD-L pathway is emerging as a major regulator of $T$ cell responses to chronic infectious and autoimmune diseases. Our data demonstrate, for the first time to our knowledge, that 
this pathway affects the systemic $\mathrm{T}$ cell response to hypercholesterolemia and the associated development of arterial disease. This knowledge should be considered for the development of immunomodulatory approaches to atherosclerosis.

\section{Methods}

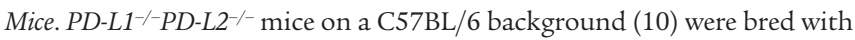
$L D L R^{-/-}$mice to produce the triple-knockout $P D-L 1 / 2^{-/-} L D L R^{-/-}$mice used in this study. $L D L R^{-/-}$mice backcrossed 10 times onto a C57BL/6 background (The Jackson Laboratory) were used as control mice in these studies. OT-II mice, which express a class II MHC (I-A $\left.{ }^{\mathrm{b}}\right)$ restricted transgenic TCR

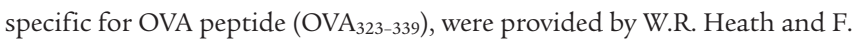
Carbone (Walter and Eliza Hall Institute of Medical Research, Melbourne, Victoria, Australia) (23). All mice were housed and bred in accordance with the institutional guidelines and were approved by the institutional review board of Brigham and Women's Hospital and Harvard Medical School.

Aortic atherosclerotic lesion analysis. Atherosclerotic lesions were analyzed in the aortic root, aortic arch, and descending aorta as previously described (17). Alternate cryosections ( $5 \mu \mathrm{m}$ thick) throughout the aortic sinus (total distance covered, approximately $200 \mu \mathrm{m}$ ) were taken for analysis. From the area in which 3 aortic valve cusps are clearly seen, alternate sections were collected for quantification. Longitudinal cryostat sections of the aortic arch, and formalin fixed, pinned-out en face preparations of the descending aorta were prepared as described previously $(15,41)$. Aortic lesions were stained with ORO according to the method of Paigen et al. (42). Images of sections were captured digitally (SV Micro) and quantified using IMAGEPRO PLUS software (Media Cybernetics). For aortic root sections, the plaque lesion area and percent of the total cross-sectional vessel wall area were quantified, and the results were expressed as the mean of 6 sections per mouse. Quantification of aortic arch and abdominal aortic lesions was performed as described $(15,41)$. Measurements and evaluation of the atherosclerotic lesions were performed in a blinded fashion.

Immunohistochemical and immunofluorescence staining. For immunohistochemical analysis, serial cryostat sections of aortic sinus adjacent to the OROstained sections were stained with the respective molecule-specific antibodies, as described previously $(21,43)$. Antibodies for immunohistochemistry included rat anti-mouse Mac-3 for macrophage identification (1:1,000; BD Biosciences - Pharmingen), and anti-CD4 ${ }^{+}$for T cells (1:120; BD Biosciences - Pharmingen). For mouse smooth muscle cell-actin staining, primary antibody (FITC-conjugated $\alpha$-actin, 1:500; Sigma-Aldrich) was applied, followed by anti-FITC biotin-conjugated secondary antibody (1:400; Sigma-Aldrich). For PD-L1 staining we used purified rat anti-mouse B7-H1 mAb clone 10F.9G2 (33). Quantitative analysis of lesional content of macrophages, smooth muscle cells, and collagen was determined by computer-assisted image analysis $(15,17)$ and expressed as percentage of intimal area in order to normalize for overall differences between the study groups. Quantification of CD4 staining was accomplished by counting individual positively stained lesional cells, which are easily resolved, in the aortic-sinus sections.

For immunofluorescence staining, serial cryostat sections $(6 \mu \mathrm{m})$ of aortic roots were fixed in acetone $\left(-20^{\circ} \mathrm{C}, 5\right.$ minutes $)$, air-dried, and blocked with $1 \%$ BSA in PBS. All primary antibodies were from BD Biosciences - Pharmingen except anti-PD-L1 (see above). For colocalization of $\mathrm{CD}^{+}$ $\mathrm{T}$ cells with $\mathrm{CD} 4^{+}$or $\mathrm{CD} 8^{+}$subsets, sections were stained with rat anti-CD4 or rat anti-CD8 antibodies, followed by biotinylated rabbit anti-rat (mouse absorbed; Vector Laboratories) secondary antibody and then streptavidinFITC (1:100; Amersham Corp.). Secondary stains were performed with rhodamine-conjugated rat anti-mouse CD3. For colocalization of PD-L1 and either $\mathrm{CD} 11 \mathrm{c}$ or Mac3, sections were first stained with rat anti-mouse PD-L1 (described above) and then incubated with biotinylated rabbit antirat secondary antibody (Vector Laboratories), followed by FITC-streptavi- din (Amersham Corp.). After blocking with an avidin/biotin blocking kit (Vector Laboratories), the sections were subsequently stained with hamster anti-mouse $\mathrm{CD} 11 \mathrm{c}$ or Mac3, followed by biotinylated anti-hamster cocktail and Texas red-conjugated streptavidin (Vector Laboratories).

Serum cholesterol analysis. Overnight fasting blood from individual mice collected after 8 weeks of cholesterol-enriched diet was allowed to clot; the serum fraction was microcentrifuged and stored at $-20^{\circ} \mathrm{C}$ until specific assays were performed. Total serum cholesterol levels, triglycerides, and plasma lipoproteins were analyzed by an online dual enzymatic method for simultaneous quantification of cholesterol and triglycerides by HPLC at Skylight Biotech Inc. according to the procedure as described by Usui et al. (44) and expressed in $\mathrm{mg} / \mathrm{dl}$.

Serum cytokine level. Serum from mice at the end of the experiment was analyzed for cytokine levels using flow cytometry-based cytokine bead assays (BD Biosciences - Pharmingen) (45).

Isolation of DCs and macrophages. DCs were isolated from minced and collagenase-treated spleens, using a commercially available kit that relies on anti-CD11c-coated magnetic beads (Miltenyi Biotec). The purity of these cells was greater than $90 \%$ CD $11 c^{+}$by FACS analysis, and greater than $90 \%$ of the $\mathrm{CD} 11 \mathrm{c}^{+}$cells were also positive for class II MHC. Peritoneal macrophages were isolated by peritoneal lavage with cold PBS. The purity of these cells was $>90 \% \mathrm{~F} 4 / 80^{+}$by FACS analysis.

Lipid loading of DCs and peritoneal macrophages. Isolated DCs and peritoneal macrophages were incubated for 5 hours in tissue culture medium with added acLDL $(100 \mu \mathrm{g} / \mathrm{ml}$; Biomedical Technologies Inc.) and the acyl CoA cholesterol acyltransferase (ACAT) inhibitor Compound 58035 (3-[decyldimethylsilyl]-N[2-(4-methylphenyl)-1-phenylethyl] propanamide; $10 \mu \mathrm{g} / \mathrm{ml})(24)$.

In vitro and ex vivo assays of $\mathrm{CD}^{+}$proliferation and cytokine secretion. For isolation of $\mathrm{CD}^{+}{ }^{+} \mathrm{T}$ cells from experimental mice on high-cholesterol diet or OT-II TCR transgenic mice, spleens were removed from the mice and CD4 ${ }^{+}$ $\mathrm{T}$ cells were isolated by anti-CD4 Microbeads (Miltenyi Biotec). The cells were stimulated in 96-well cultures $\left(1 \times 10^{5}\right.$ cells/well $)$ with plate-bound anti-CD3ع (145-2C11; BD Biosciences - Pharmingen), human copper-oxidized LDL (Biomedical Technologies Inc.), or OVA peptide ( $\left.\mathrm{OVA}_{323-339}\right)$ plus irradiated T cell-depleted spleen cells $\left(1 \times 10^{6}\right.$ cells/well $)$ as APCs. Medium alone was used as a control. For in vitro stimulation with peritoneal macrophages or DCs, the T cells were stimulated at the ratios indicated in Results and in the figure legends. Culture supernatants were removed at 48 hours and analyzed by flow cytometry-based cytokine bead assays (BD Biosciences - Pharmingen) of culture supernatants for IFN- $\gamma$ and IL-2 cytokines (45). Cultures were assayed for proliferation after 64 hours by $[3 \mathrm{H}]$-thymidine uptake $(1 \mu \mathrm{Ci} /$ well), added 16 hours before harvest.

Flow cytometry. We performed 2- or 3-color flow cytometry by standard protocol. Briefly, $0.5-1 \times 10^{6}$ cells from spleens were incubated in $100 \mu \mathrm{l}$ staining buffer (PBS with $1 \%$ BSA) and Fcy III/II Receptor blocking antibody (2.4G2; BD Biosciences - Pharmingen) for 10 minutes. The cells were then stained with a mixture of PE-, FITC-, PE-Cy5-, or APC-conjugated mAb $(0.5$ $\mu \mathrm{g} /$ sample) for 15 minutes, washed twice, then fixed in PBS with $1 \%$ formaldehyde. The analysis was performed on a FACSCalibur flow cytometer (BD Biosciences) with CellQuest software (BD Biosciences). All procedures were performed on ice until analysis. The mAbs for flow cytometry were as follows: APC-conjugated F4/80 (Caltag/Invitrogen), APC-conjugated CD11c (BD Biosciences), PE-conjugated PD-L1 (BD Biosciences), FITC-conjugated PD-L2 (BD Biosciences), FITC-conjugated B7-1 (BD Biosciences), PE-conjugated anti-CD25 (PC61; BD Biosciences), and FITC-conjugated anti-CD4 (L3T4; BD Biosciences). The fraction of positive-staining cells was determined relative to isotype control-stained cells.

Statistics. All statistical analyses were performed using Prism software. Differences between mice were analyzed by Student's $t$ test and expressed as mean \pm SEM or by the Mann-Whitney test (for nonparametric data). 
Differences among multiple groups were determined by the Kruskal-Wallis test and the Dunn's multiple-comparison test. A P value of 0.05 or less was considered significant for all analyses.

\section{Acknowledgments}

This work was supported by NIH grants P50HL56985 and R01HL087282 (A.H. Lichtman) and R01AI46414 and PO1AI056299 (A.H. Sharpe).

1. Hansson, G.K. 2001. Immune mechanisms in atherosclerosis. Arterioscler. Thromb. Vasc. Biol. 21:1876-1890.

2. Zhou, X., Robertson, A.K., Rudling, M., Parini, P., and Hansson, G.K. 2005. Lesion development and response to immunization reveal a complex role for CD4 in atherosclerosis. Circ. Res. 96:427-434.

3. Zhou, X., Robertson, A.K., Hjerpe, C., and Hansson, G.K. 2006. Adoptive transfer of CD4+ T cells reactive to modified low-density lipoprotein aggravates atherosclerosis. Arterioscler. Thromb. Vasc. Biol. 26:864-870.

4. Wick, G., Knoflach, M., and Xu, Q. 2004. Autoimmune and inflammatory mechanisms in atherosclerosis. Annu. Rev. Immunol. 22:361-403.

5. Hansson, G.K., and Libby, P. 2006. The immune response in atherosclerosis: a double-edged sword. Nat. Rev. Immunol. 6:508-519.

6. Gupta, S., et al. 1997. IFN- $\gamma$ potentiates atherosclerosis in ApoE knock-out mice. J. Clin. Invest. 99:2752-2761.

7. Buono, C., et al. 2003. Influence of interferongamma on the extent and phenotype of dietinduced atherosclerosis in the LDLR-deficient mouse. Arterioscler. Thromb. Vasc. Biol. 23:454-460.

8. Sharpe, A.H., and Freeman, G.J. 2002. The B7CD28 superfamily. Nat. Rev. Immunol. 2:116-126.

9. Greenwald, R.J., Freeman, G.J., and Sharpe, A.H. 2005. The B7 family revisited. Annu. Rev. Immunol. 23:515-548

10. Keir, M.E., Latchman, Y.E., Freeman, G.J., and Sharpe, A.H. 2005. Programmed death-1 (PD-1): PD-ligand 1 interactions inhibit TCR-mediated positive selection of thymocytes. J. Immunol. 175:7372-7379.

11. Latchman, Y., et al. 2001. PD-L2 is a second ligand for PD-1 and inhibits T cell activation. Nat. Immunol. 2:261-268.

12. Freeman, G.J., et al. 2000. Engagement of the PD-1 immunoinhibitory receptor by a novel B7 family member leads to negative regulation of lymphocyte activation. J. Exp. Med. 192:1027-1034.

13. Cai, G., et al. 2004. PD-1 ligands, negative regulators for activation of naive, memory, and recently activated human CD4+ T cells. Cell. Immunol. 230:89-98.

14. Kanai, T., et al. 2003. Blockade of B7-H1 suppresses the development of chronic intestinal inflammation. J. Immunol. 171:4156-4163.

15. Buono, C., et al. 2004. B7-1/B7-2 co-stimulation regulates plaque antigen-specific $T$ cell responses and atherogenesis in LDLR-deficient mice. Circulation. 109:2009-2015.

16. Ait-Oufella, H., et al. 2006. Natural regulatory T cells control the development of atherosclerosis in mice. Nat. Med. 12:178-180.
Received for publication December 26, 2006, and accepted in revised form June 26, 2007.

Address correspondence to: Andrew H. Lichtman, Department of Pathology, Brigham and Women's Hospital, 77 Avenue Louis Pasteur, NRB 752N, Boston, Massachusetts 02115, USA. Phone: (617) 525-4335; Fax: (617) 525-4333; E-mail: alichtman@ rics.bwh.harvard.edu.
17. Gotsman, I., et al. 2006. Impaired regulatory $\mathrm{T}$-Cell response and enhanced atherosclerosis in the absence of inducible costimulatory molecule. Circulation. 114:2047-2055.

18. Latchman, Y.E., et al. 2004. PD-L1-deficient mice show that PD-L1 on T cells, antigen-presenting cells, and host tissues negatively regulates $\mathrm{T}$ cells. Proc. Natl. Acad. Sci. U. S. A. 101:10691-10696.

19. Keir, M.E., et al. 2006. Tissue expression of PD-L1 mediates peripheral T cell tolerance. J. Exp. Med. 203:883-895.

20. Rodig, N., et al. 2003. Endothelial expression of PD-L1 and PD-L2 down-regulates CD8+ T cell activation and cytolysis. Eur. J. Immunol. 33:3117-3126

21. Liang, S.C., et al. 2003. Regulation of PD-1, PD-L1, and PD-L2 expression during normal and autoimmune responses. Eur. J. Immunol. 33:2706-2716.

22. Li, A.C., et al. 2004. Differential inhibition of macrophage foam-cell formation and atherosclerosis in mice by $\operatorname{PPAR} \alpha, \beta / \delta$, and $\gamma$. J. Clin. Invest. 114:1564-1576. doi:10.1172/JCI200418730.

23. Li, M., et al. 2001. Cell-associated ovalbumin is cross-presented much more efficiently than soluble ovalbumin in vivo. J. Immunol. 166:6099-6103.

24. Leventhal, A.R., Leslie, C.C., and Tabas, I. 2004. Suppression of macrophage eicosanoid synthesis by atherogenic lipoproteins is profoundly affected by cholesterol-fatty acyl esterification and the Niemann-Pick C pathway of lipid trafficking. J. Biol. Chem. 279:8084-8092.

25. Angeli, V., et al. 2004. Dyslipidemia associated with atherosclerotic disease systemically alters dendritic cell mobilization. Immunity. 21:561-574.

26. Bobryshev, Y.V. 2005. Dendritic cells in atherosclerosis: current status of the problem and clinical relevance. Eur. Heart J. 26:1700-1704.

27. Koga, N., et al. 2004. Blockade of the interaction between PD-1 and PD-L1 accelerates graft arterial disease in cardiac allografts. Arterioscler. Thromb. Vasc. Biol. 24:2057-2062.

28. Liang, S.C., et al. 2006. PD-L1 and PD-L2 have distinct roles in regulating host immunity to cutaneous leishmaniasis. Eur. J. Immunol. 36:58-64.

29. Zhu, B., et al. 2006. Differential role of programmed death-ligand 1 and programmed death-ligand 2 in regulating the susceptibility and chronic progression of experimental autoimmune encephalomyelitis. J. Immunol. 176:3480-3489.

30. Salama, A.D., et al. 2003. Critical role of the programmed death-1 (PD-1) pathway in regulation of experimental autoimmune encephalomyelitis. J. Exp. Med. 198:71-78.

31. Ansari, M.J., et al. 2003. The programmed death-1 (PD-1) pathway regulates autoimmune diabetes in nonobese diabetic (NOD) mice. J. Exp. Med.
198:63-69.

32. Ding, Q., et al. 2006. B7H1-Ig fusion protein activates the CD4+ IFN-gamma receptor+ type $1 \mathrm{~T}$ regulatory subset through IFN-gamma-secreting Th1 cells. J. Immunol. 177:3606-3614.

33. Eppihimer, M.J., et al. 2002. Expression and regulation of the PD-L1 immunoinhibitory molecule on microvascular endothelial cells. Microcirculation. 9:133-145.

34. Schoop, R., et al. 2004. Suppressed T-cell activation by IFN-gamma-induced expression of PD-L1 on renal tubular epithelial cells. Nephrol. Dial. Transplant. 19:2713-2720.

35. Llodra, J., et al. 2004. Emigration of monocytederived cells from atherosclerotic lesions characterizes regressive, but not progressive, plaques. Proc. Natl. Acad. Sci. U. S. A. 101:11779-11784.

36. Ludewig, B., et al. 2001. Hypercholesterolemia exacerbates virus-induced immunopathologic liver disease via suppression of antiviral cytotoxic $\mathrm{T}$ cell responses. J. Immunol. 166:3369-3376.

37. Robertson, A.K., and Hansson, G.K. 2006. T cells in atherogenesis: for better or for worse? Arterioscler. Thromb. Vasc. Biol. 26:2421-2432.

38. Trautmann, L., et al. 2006. Upregulation of PD-1 expression on HIV-specific CD8(+) T cells leads to reversible immune dysfunction. Nat. Med. 12:1198-1202

39. Freeman, G.J., Wherry, E.J., Ahmed, R., and Sharpe, A.H. 2006. Reinvigorating exhausted HIV-specific T cells via PD-1-PD-1 ligand blockade. J. Exp. Med. 203:2223-2227.

40. Day, C.L., et al. 2006. PD-1 expression on HIV-specific $\mathrm{T}$ cells is associated with T-cell exhaustion and disease progression. Nature. 443:350-354.

41. Buono, C., et al. 2005. T-bet deficiency reduces atherosclerosis and alters plaque antigen-specific immune responses. Proc. Natl. Acad. Sci. U. S. A. 102:1596-1601.

42. Paigen, B., Morrow, A., Holmes, P.A., Mitchell, D. and Williams, R.A. 1987. Quantitative assessment of atherosclerotic lesions in mice. Atherosclerosis. 68:231-240.

43. Grabie, N., et al. 2003. IL-12 is required for differentiation of pathogenic $\mathrm{CD}^{+} \mathrm{T}$ cell effectors that cause myocarditis. J. Clin. Invest. 111:671-680. doi:10.1172/JCI200316867.

44. Usui, S., Hara, Y., Hosaki, S., and Okazaki, M. 2002. A new on-line dual enzymatic method for simultaneous quantification of cholesterol and triglycerides in lipoproteins by HPLC. J. Lipid Res. 43:805-814.

45. Dong, H., Zhu, G., Tamada, K., and Chen, L. 1999. B7-H1, a third member of the B7 family, co-stimulates T-cell proliferation and interleukin-10 secretion. Nat. Med. 5:1365-1369. 